\title{
Detection of Anti-Toxoplasma gondii Antibodies in Human Sera Using Synthetic Glycosylphosphatidylinositol Glycans on a Bead- Based Multiplex Assay
}

\author{
Monika Garg, ${ }^{\dagger, \ddagger}, \#$ Daniel Stern, ${ }^{\S, \# \odot ~ U w e ~ G r o ß, ~}{ }^{\|}$Peter H. Seeberger, ${ }^{\dagger,}$ Frank Seeber, ${ }^{\perp}$ \\ and Daniel Varón Silva*, ${ }^{*}, \$$ (i) \\ ${ }^{\dagger}$ Department of Biomolecular Systems, Max Planck Institute of Colloids and Interfaces, 14424 Potsdam, Germany \\ ${ }^{\ddagger}$ Department of Chemistry and Biochemistry, Freie Universität Berlin, Arnimallee 22, 14195 Berlin, Germany \\ ${ }^{\S}$ ZBS 3 - Biological Toxins and ${ }^{\perp}$ FG 16 - Mycotic and Parasitic Agents and Mycobacteria, Robert Koch Institute, 13353 Berlin, \\ Germany \\ "German Consulting Laboratory for Toxoplasma, Institute for Medical Microbiology, University Medical Center Göttingen, 37075 \\ Goettingen, Germany
}

Supporting Information

ABSTRACT: Toxoplasmosis, while often an asymptomatic parasitic disease in healthy individuals, can cause severe complications in immunocompromised persons and during pregnancy. The most common method to diagnose Toxoplasma gondii infections is the serological determination of antibodies directed against parasite protein antigens. Here we report the use of a bead-based multiplex assay containing a synthetic phosphoglycan portion of the Toxoplasma gondii glycosylphosphatidylinositol (GPI1) for the detection of GPI1-specific antibodies in human sera. The glycan was conjugated to beads at the lipid site to retain its natural orientation and its immunogenic groups. We compared the response against GPI1 with that against the protein antigen SAG1, a common component of commercial serological assays, via the detection of parasite-specific human IgG and IgM antibodies, respectively. The GPI1-based test is in excellent agreement with the results for the commercial ELISA, as the ROC analysis of the GPI1 test shows $97 \%$ specificity and $98 \%$ sensitivity for the assay. GPI1 was a more reliable predictor for a parasite-specific IgM response compared to SAG1, indicating that a bead-based multiplex assay using GPI1 in combination with SAG1 may strengthen Toxoplasma gondii serology, in particular in seroepidemiological studies.
A round one-third of the world's population is chronically infected by Toxoplasma gondii, a globally distributed apicomplexan parasite that infects all warm blooded animals. ${ }^{1}$ Humans get infected with $T$. gondii mainly by ingesting raw or undercooked meat from infected animals, by food contaminated with $T$. gondii oocysts, ${ }^{2}$ and rarely by organ transplants from infected individuals. ${ }^{3}$ Generally, T. gondii infections in healthy individuals are asymptomatic or induce only mild flulike symptoms. In immunocompromised individuals $T$. gondii infections can lead to serious complications such as toxoplasmic encephalitis and/or ocular toxoplasmosis resulting in blindness if not treated. ${ }^{4}$ Importantly, during pregnancy, a primary infection with $T$. gondii can lead to transmission of the parasites from mother to child, causing physical or mental retardation of the infant or even induce abortion. ${ }^{4}$

T. gondii infections are primarily diagnosed by serological detection of IgM and IgG antibodies, and in some cases IgA, directed against parasitic protein antigens. ${ }^{5}$ Commercial assays rely on antigens derived from whole $T$. gondii lysate, purified

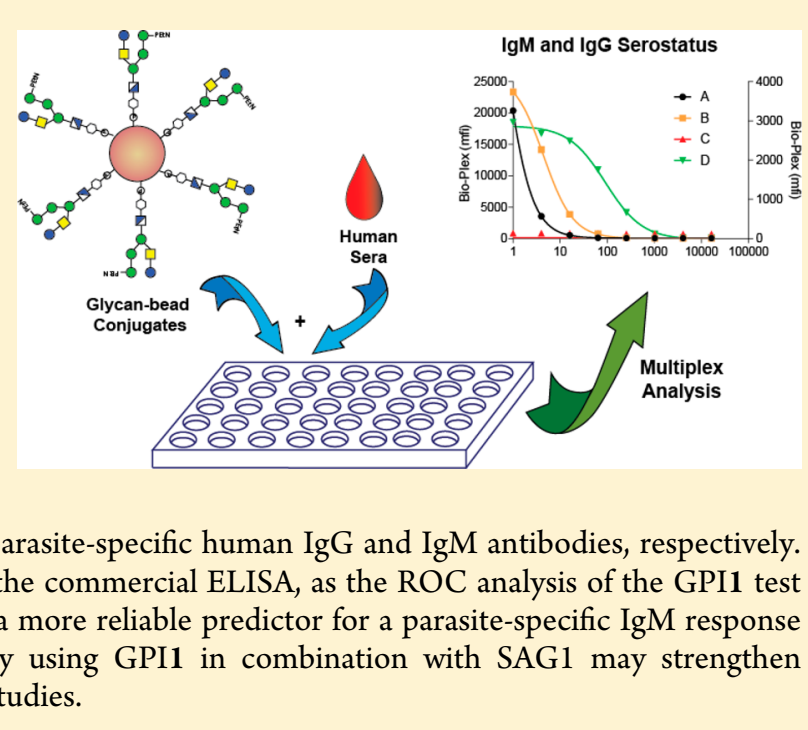

from parasites grown in mice or cell culture, or from recombinant sources. ${ }^{6,7}$ Antibodies are detected primarily by immunochemical methods such as enzyme-linked immunosorbent assay (ELISA), but indirect fluorescent antibody test (IFAT), immunosorbent agglutination assay (ISAGA), modified agglutination tests (MAT), or indirect hemagglutination assays (IHA) have also been used. ${ }^{7}$ These methods cannot estimate the time point of the initial infection. In pregnant women, the presence of IgM antibodies may mark a recently acquired, acute infection. In this case, additional tests for IgG and IgM avidity may be essential to determine whether the infection occurred in a seronegative mother after conception (primary infection). Thus, multiple assays are often used to confirm the infection but might also call for several

Received: May 7, 2019

Accepted: August 12, 2019

Published: August 12, 2019 
confirmatory tests by specialized diagnostic laboratories, ${ }^{8}$ requiring a larger volume of sera to be collected. In the case of large-scale seroepidemiological studies access to serum is limited, in particular from small children and in developing countries. $^{9-11}$ Determination of $\operatorname{IgG}$ and/or IgM responses against several pathogens is desirable and also sufficient to obtain estimates of prevalence of acute and chronic infections. Therefore, assay formats allowing a parallel determination of multiple analytes are ideal for these studies.

Bead-based multiplex assays (BBMAs) are high throughput methods for the simultaneous detection and quantification of multiple analytes and samples. ${ }^{12}$ BBMAs use color-coded beads that carry the antigen of interest. By addition of serum samples, specific antibodies bind to the bead-coupled antigen, which are detected using a secondary, fluorescence-labeled detection antibody (Figure 1a). A reader with two detection

\section{a)}
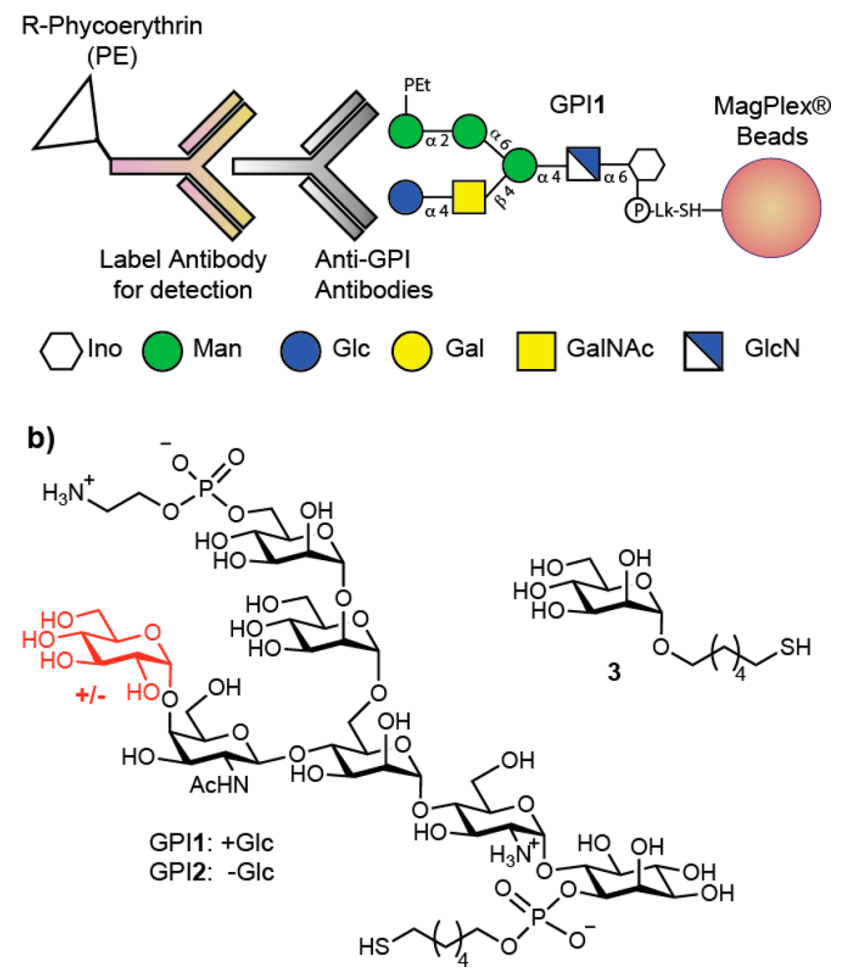

Figure 1. Detection of glycosylphosphatidylinositols of T. gondii parasites. (a) Symbolic representation of the detection of anti-GPI antibodies using the BBMA. (b) Chemical representation showing the variations of $T$. gondii's GPIs.

channels separates the beads according to color code and detects the intensity of the fluorescent label on the secondary antibody, respectively. This method is faster and requires less sample than conventional methods to detect specific antibodies.

Glycosylphosphatidylinositols (GPIs) are complex glycolipids on the cell surface of eukaryotes that are present either in protein-free form or used to anchor proteins to the cell membrane. Two main GPI glycoforms are present on the surface of T. gondii, a free GPI also known as the low molecular weight antigen (GPI1), ${ }^{13}$ and GPI2 that anchors proteins such as surface antigen SAG1 to the parasite membrane (Figure 1). ${ }^{14,15}$ Synthetic GPI glycans fixed on array surfaces can be used to detect IgG and IgM anti-GPI antibodies in sera from infected individuals and to differentiate acute and latent toxoplasmosis infections. $^{16}$

Here we report the use of a synthetic GPI-glycan conjugated to color-coded magnetic beads to detect anti-GPI1 antibodies using a BBMA. This high-throughput method can simultaneously detect anti-SAG1 and anti-GPI1 antibodies with diagnostic value for toxoplasmosis and enable large-scale seroepidemiological studies. ${ }^{17}$ Furthermore, our data show that comparing IgM responses directed against SAG1 and GPI1 could allow the discrimination between acute and postacute/latent infections.

\section{MATERIALS AND METHODS}

Serum Panel of Human Sera and Reference Measurements for Analysis of Anti-T. gondii Antibodies. Serum samples of anonymous donors were taken from a large collection of human sera from the 1980s. These sera were obtained during routine serosurveillance studies performed in the former German Democratic Republic (now in possession of the Robert Koch-Institute) and known to possess a high proportion $(>50 \%)$ of sera positive for anti-T. gondii antibodies. ${ }^{18}$ These sera were sampled each year in 4-5 government districts (out of 15), collecting 150-200 samples from 10 age groups ( 0 to $>60$ years). Sera were heat inactivated. No further data are available. It has been shown that even old sera still perform very well in serology, including testing for T. gondii. ${ }^{19,20}$ Out of this collection, random samples were picked and analyzed for the presence of anti- $T$. gondii IgG antibodies using a commercial ELISA kit (Euroimmun, Lübeck, Germany) following the supplier's instructions. These sera are referred to as population-based panel (PBP) sera. In addition, human sera from infected individuals tested positive for anti- $T$. gondii $\operatorname{IgM} / \operatorname{IgG}$ by routine diagnosis using the VIDAS TOXO IgM or IgG (bioMérieux) enzymelinked fluorescent immunoassays (ELIFA), scored positive using the manufacturer's recommended value for $\operatorname{IgM}(\geq 0.65)$ or a cutoff value of $8 \mathrm{IU} / \mathrm{mL}$ for IgG, were included. These sera were classified as follows: (i) acute (1-3 months postinfection (pi); high IgM concentrations and/or presence of $\operatorname{IgA}$ antibodies and/or low IgG avidity and/or IFA $\geq$ 1:1024), $n=7$; (ii) postacute ( $>3$ months pi; IgG avidity high and/or IFA < 1:1024), $n=3$; (iii) latent infection with IgM persistence (low IgM concentrations or proven previous infection $>2$ years, and/or high IgG avidity, and/or IFA < $1: 1024), n=6$. No ethical clearance was necessary because these serum samples were obtained for routine diagnosis and used here without personalized data. Reference sera $13 / 132^{21}$ and $01 / 600^{22}$ were used for quantification of anti-T. gondii IgG in international units (IU) and were obtained from the National Institute for Biological Standards and Control (NIBSC), UK.

Synthetic GPI Phosphoglycan from T. gondii. The phosphoglycan part of the glycosylphosphatidylinositol (GPI1) from $T$. gondii was synthesized following established protocols. $^{23,24}$ A phosphate-alkyl-thiol linker replacing the natural phospholipid was installed at the O-1 position of myoinositol and used for conjugation of the GPI1 glycan to MagPlex beads modified with a maleimide (see below).

Glycan Microarray Detection of Anti-GPI Antibodies Using Microarrays. Glycans were dissolved (final concentration of $250 \mu \mathrm{M}$ ) in phosphate buffer $\mathrm{pH} 7.4$ including 250 $\mu \mathrm{M}$ of TCEP. The compounds were robotically printed onto sciCHIP epoxy glass slides using the piezoelectric spotting 
device S3 (Scienion) at 50\% relative humidity and $23{ }^{\circ} \mathrm{C}$. The preparation and analysis of sera were performed according to previously established protocols. ${ }^{16}$ In brief, each serum sample was diluted 1:15 with PBS ( $\mathrm{pH} 7.4$ ) containing $0.1 \% \mathrm{v} / \mathrm{v}$ Tween 20 and $3 \% \mathrm{w} / \mathrm{v}$ BSA and incubated at $37^{\circ} \mathrm{C}$ for $15 \mathrm{~min}$ to dissolve potential lipid aggregates. The microarrays were blocked with BSA $(2.5 \%, \mathrm{w} / \mathrm{v})$ in PBS for $1 \mathrm{~h}$ at room temperature, washed twice with PBS and water, and dried by centrifugation ( $3 \mathrm{~min}, 300 \mathrm{~g}$ ). The sera were added to the microarrays and deposited in a sealed humidified incubator for $1 \mathrm{~h}$ at room temperature. Unbound sample components were removed with a series of washes with $0.1 \%(1 \times)$ and twice with $0.001 \% \mathrm{v} / \mathrm{v}$ Tween 20 in PBS. The microarrays were incubated for $1 \mathrm{~h}$ at room temperature with ALEXA-Fluor594 goat antihuman-IgM antibody ( $\mu$-chain specific form; Life Technologies) or ALEXA-Fluor488 antihuman-IgG antibody (Fc $\gamma$ specific, from Dianova) diluted 1:400 in PBS containing 0.1\% v/v Tween 20 and 3\% w/v BSA. The slides were washed $(1 \times)$ with PBS ( $\mathrm{pH} 7.4$ ) containing $0.1 \% \mathrm{v} / \mathrm{v}$ Tween 20 and $3 \% \mathrm{w} / \mathrm{v}$ BSA, PBS $(1 \times)$, and water $(1 \times)$ and subsequently dried by centrifugation ( $5 \mathrm{~min}, 300 \mathrm{~g}$ ). The slides were analyzed using a fluorescence microarray scanner (Genepix 4300A, Molecular Devices) using a PMT gain that saturated the highest signals to a minimum amount to ensure reproducibility. All analyzed spots were manually adjusted and the "mean fluorescence values - background" was used for analysis.

Modification of MagPlex Microspheres. Carboxylfunctionalized MagPlex magnetic microspheres of region 20 (Luminex) were modified with a $\mathrm{N}$-propylaminomaleimide linker using the method described in the xMAP reference book. ${ }^{25}$ Briefly, $100 \mu \mathrm{L}$ of the stock suspension (approximately $1.25 \times 10^{6}$ beads) of carboxyl-functionalized microspheres were centrifuged and separated. The microspheres were resuspended in $500 \mu \mathrm{L}$ of $0.1 \mathrm{M}$ 2-(N-morpholino)ethanesulfonic acid (MES) buffer $\mathrm{pH}$ 6.0, vortexed, sonicated for $20 \mathrm{~s}$, and pelleted with a magnet. The supernatant was removed, the beads were resuspended in $100 \mu \mathrm{L}$ of $0.1 \mathrm{M}$ MES, $\mathrm{pH} 6.0$, containing $1 \mathrm{mg} / \mathrm{mL}$ of $N$-propylaminomaleimide (see SI for preparation), and $50 \mu \mathrm{L}$ of a $10 \mathrm{mg} / \mathrm{mL}$ EDC solution (freshly prepared in $0.1 \mathrm{M} \mathrm{MES}, \mathrm{pH}$ 6.0) was added. The microspheres were incubated for $2 \mathrm{~h}$ under continuous mixing at room temperature. The reaction was quenched by addition of $250 \mu \mathrm{L}$ of $0.1 \mathrm{M}$ MES, $\mathrm{pH} 4.5$, and mixing. The beads were pelleted, the supernatant was removed and the microspheres were washed twice with $250 \mu \mathrm{L}$ of $0.1 \mathrm{M}$ MES, $\mathrm{pH}$ 4.5. Finally, the microspheres were resuspended in $250 \mu \mathrm{L}$ of $0.1 \mathrm{M} \mathrm{MES}, \mathrm{pH} 4.5$, and stored at $4{ }^{\circ} \mathrm{C}$ in the dark or used immediately for the coupling of the thiol linked glycan.

Coupling of Glycans to the Maleimide-Coupled MagPlex Beads. The glycan disulfides were reduced by treatment with 1.1 equiv of resin-bound tris(2-carboxyethyl)phosphine (TCEP, Sigma-Aldrich) in 0.1 M PBS buffer (0.1M sodium phosphate, $50 \mathrm{mM} \mathrm{NaCl}, \mathrm{pH} 7.0$ ). The resin was removed, and the solution was lyophilized. Maleimidemodified beads $\left(1.25 \times 10^{6}\right.$ microspheres $)$ were washed with $0.1 \mathrm{M}$ PBS and resuspended in $100 \mu \mathrm{L}$ of the same buffer. A 50 $\mu \mathrm{g}$ amount of the freshly reduced GPI1 glycan was dissolved in $100 \mathrm{mM}$ Tris buffer $\mathrm{pH}$ 7.4. The GPI1 solution was added to the beads, and the final volume was adjusted to $250 \mu \mathrm{L}$ with $100 \mathrm{mM}$ Tris buffer, $\mathrm{pH}$ 7.4. The reaction mixture was incubated at room temperature in darkness. After $1 \mathrm{~h}$, the microspheres were pelleted and the supernatant was removed. The unreacted maleimide groups were quenched by addition of $100 \mu \mathrm{L}$ of a $50 \mathrm{mM} \mathrm{L-cysteine} \mathrm{hydrochloride} \mathrm{solution} \mathrm{in} 100$ $\mathrm{mM}$ Tris buffer, $\mathrm{pH}$ 7.4. After $1 \mathrm{~h}$, the microspheres were pelleted, washed twice with $100 \mu \mathrm{L}$ of $0.1 \mathrm{M}$ PBS containing $1 \% \mathrm{BSA}$, and stored in $250 \mu \mathrm{L}$ of $0.1 \mathrm{M}$ PBS-TBN buffer at 4 ${ }^{\circ} \mathrm{C}$.

Determination of the GPI1 Coupling Efficacy to MagPlex Beads. GPI-beads $\left(5 \times 10^{5}\right)$ were washed with water and hydrolyzed using $200 \mu \mathrm{L}$ of $2 \mathrm{M}$ TFA for $4 \mathrm{~h}$ at 100 ${ }^{\circ} \mathrm{C}$. The hydrolysis mixture was lyophilized, and the remainder was dissolved in $100 \mathrm{~mL}$ of water and analyzed on a CarboPac PA20 column $(3 \times 150 \mathrm{~mm}$, Dionex $)$ using a highperformance anion exchange chromatography system coupled with a pulsed amperometer detector (HPAE-PAD, Dionex, Sunnyvale, CA). The monosaccharides were separated using isocratic $10 \mathrm{mM} \mathrm{NaOH}$ (J.T. Baker, Devneter, The Netherlands) at $0.5 \mathrm{~mL} / \mathrm{min}$ flow rate for $15 \mathrm{~min}$ at $30{ }^{\circ} \mathrm{C}$. The quantity of GPI was calculated based on the content of glucose in the injected samples. The amount of glucose was determined using a calibration curve between 0 to $400 \mathrm{pmol}$ of the monosaccharide standards galactosamine, glucosamine, and glucose (Sigma).

Coupling of Antihuman IgG, Human Serum Albumin (HSA), and SAG1 Protein to MagPlex Beads. Carboxylfunctionalized MagPlex beads $\left(1.5 \times 10^{6}\right.$ microspheres $)$ of regions 7 and 15 were transferred to an Eppendorf tube (LoBind), washed with $100 \mu \mathrm{L}$ of water, resuspended in $80 \mu \mathrm{L}$ of $100 \mathrm{mM} \mathrm{NaH} \mathrm{PO}_{4}$ buffer $\mathrm{pH} 6.2$, mixed, and sonicated for $20 \mathrm{~s}$. Sulfo-NHS $(10 \mu \mathrm{L}$ of $50 \mathrm{mg} / \mathrm{mL})$ and EDC $(10 \mu \mathrm{L}$ of 50 $\mathrm{mg} / \mathrm{mL}$ ) were added, and the reaction mixture was incubated for $20 \mathrm{~min}$ at room temperature under gentle mixing. The microspheres were separated and resuspended in $100 \mu \mathrm{L}$ of 50 $\mathrm{mM}$ MES $\mathrm{pH} 5.0$ buffer and washed twice with the same buffer. The activated microspheres were resuspended in 100 $\mu \mathrm{L}$ of $50 \mathrm{mM}$ MES buffer and sonicated for $20 \mathrm{~s}$, and then 20 $\mu \mathrm{g}$ of the corresponding protein, human serum albumin (HSA, Sigma-Aldrich) or antihuman IgG (Fc $\gamma$ specific, Dianova), was added. The volume was adjusted to $500 \mu \mathrm{L}$ with $50 \mathrm{mM}$ MES buffer, and the reaction mixture was incubated for $2 \mathrm{~h}$ under mixing by rotation at room temperature. The beads were separated, washed once with $500 \mu \mathrm{L}$ and twice with $1 \mathrm{~mL}$ of PBS-TBN buffer (PBS pH 7.3, 0.1\% w/v BSA, $0.02 \% \mathrm{v} / \mathrm{v}$ Tween $20,0.05 \% \mathrm{w} / \mathrm{v}$ sodium azide), and finally stored in 500 $\mu \mathrm{L}$ of the same buffer at $4{ }^{\circ} \mathrm{C}$. Coupling of T. gondii SAG1 protein (recombinantly expressed and purified in E. coli as described ${ }^{26}$ but in biotinylated form) was performed via biotin binding to recombinant streptavidin (AnaSpec, Fremont, CA), which had been coupled to beads of region $33(25 \mu \mathrm{g})$ as described above. To this aim, a complete batch of SA-coupled beads was suspended in $100 \mu \mathrm{L}$ of PBS/BSA (0.1\%) to which $10 \mu \mathrm{g}$ of SAG1 was added. The beads were incubated subsequently for $1 \mathrm{~h}$ at room temperature in a mixer at 600 rpm, washed twice with PBS/BSA (0.1\%), and resuspended in $500 \mu \mathrm{L}$ of PBS/BSA. After coupling, all beads were counted using a counting chamber and adjusted to a concentration of 1000 beads $/ \mu \mathrm{L}$.

Detection of Anti-GPI Antibodies Using the BeadBased Multiplex Immunoassay. Successful determination of anti-GPI antibodies was first evaluated by incubation of the loaded beads with $T$. gondii-positive reference sera, namely the fourth IS WHO international standard 13/132 (containing 320 $\mathrm{IU} / \mathrm{mL}$ anti- $T$. gondii IgG antibodies) and the WHO International Standard anti-T. gondii IgG 01/600 (containing $20 \mathrm{IU} / \mathrm{mL}$ ). The immunoassays were performed in 96-well 
a)

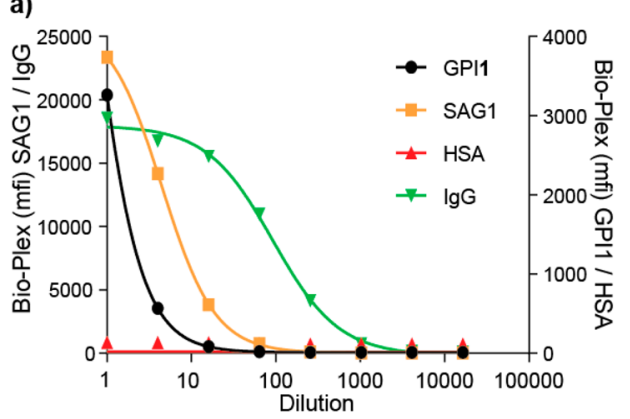

d)

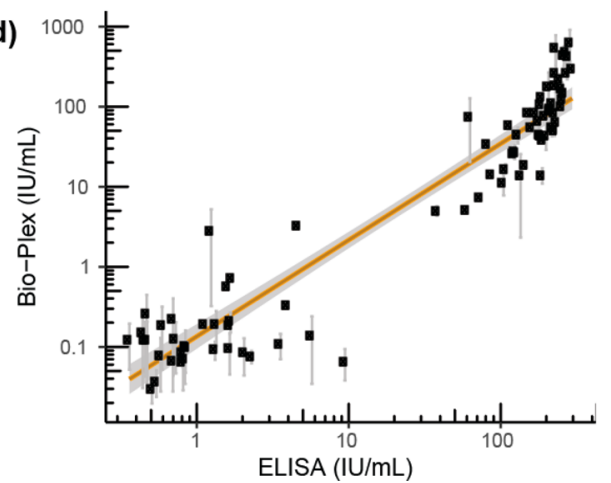

b)

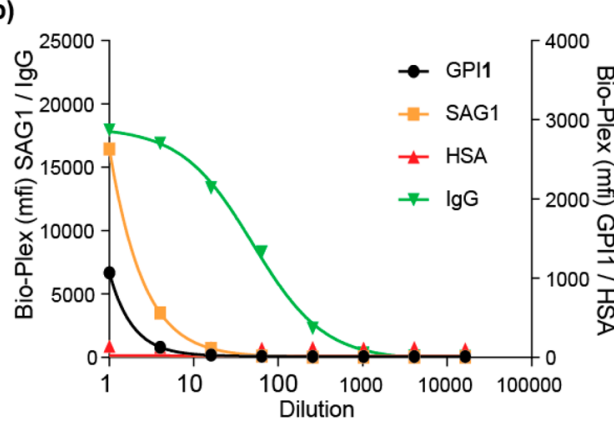

e)

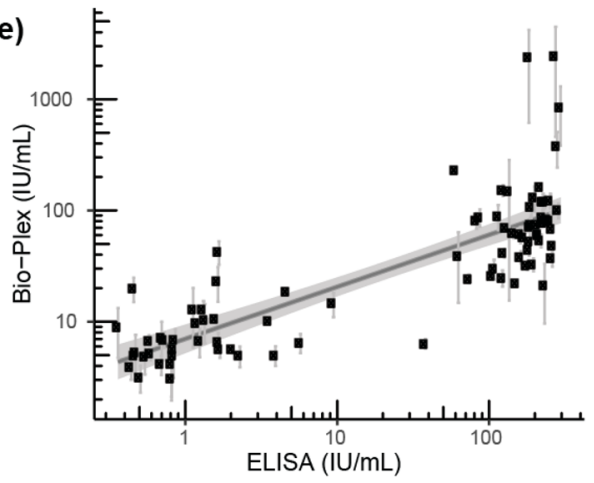

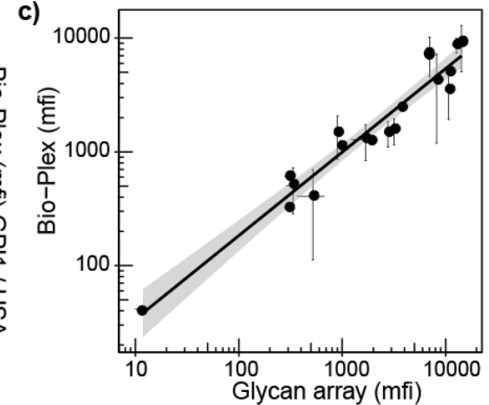

f)

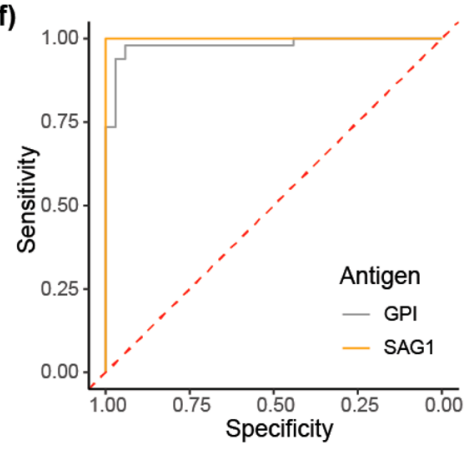

Figure 2. Binding of WHO reference sera 13/132 (a) or 01/600 (b) to GPI1-, SAG1-, HSA-, or antihuman IgG-coupled beads, respectively. IgG antibodies were quantified by detection with goat antihuman IgG PE-coupled antibodies in a 4-plex assay. Comparison of results obtained by glycan microarray and the BBMA ( $n=19$; mean of two independent experiments \pm SD for the BBMA results). Shaded area indicates the confidence interval (95\%). Comparison between ELISA and (a) SAG1 or (b) GPI1 used in the Bio-Plex assay for the quantification of the anti-T. gondii IgG immune response ( $n=82$ for SAG1 and 83 for GPI1). (c) Receiver-operator curves to determine sensitivity and specificity for determination of $T$. gondii immune status by either GPI1 or SAG1 in comparison to the ELISA (cutoff $=10 \mathrm{IU} / \mathrm{mL}$ ). Bioplex results were determined in two independent experiments (shown is mean \pm SD). Shaded areas indicate $95 \%$ CI.

plates (Greiner Bio-One) following recommendations in the xMAP cookbook for serological assay. ${ }^{25}$ For quantification, the international standard $13 / 132$ was used at a 1:4 dilution series starting at a 1:200 dilution in PBS pH 7.3, 1\% BSA (PBS-B) assay buffer (seven dilutions total including a negative control containing assay buffer only) while all sera were tested at a 1:200 dilution. The multiplex bead mix consisted of 1000 beads per bead region per well in $50 \mu \mathrm{L}$ of assay buffer. First, $50 \mu \mathrm{L}$ of the diluted standard and sera and $50 \mu \mathrm{L}$ of bead mix were added per well (GPI1 (region 20), SAG1 (region 33), antihuman IgG (region 15) and HSA (region 7)). The plate was incubated protected from light for $1 \mathrm{~h}$ at room temperature under constant shaking at $600 \mathrm{rpm}$. Next, the beads were washed with $2 \times 200 \mu \mathrm{L}$ of PBS-T $(0.1 \%$ Tween 20) washing buffer using a magnetic plate washer (Tecan HydroSpeed). To detect the bound antibodies, $100 \mu \mathrm{L}$ of $R$ phycoerythrin (PE)-coupled AffinityPure goat antihuman IgG, $\mathrm{Fc} \gamma$ fragment specific or goat antihuman IgM, Fc $5 \mu$ fragment specific (both diluted to $1 \mu \mathrm{g} / \mathrm{mL}$ in assay buffer, both from Dianova) was added, and the mixture was incubated protected from light for $60 \mathrm{~min}$ as before. Subsequently, the beads were washed with $3 \times 200 \mu \mathrm{L}$ of washing buffer and resuspended in $120 \mu \mathrm{L} /$ well assay buffer before analysis using a Bio-Plex 200 system at normal detector gain. The mean fluorescence intensity ( $\mathrm{mfi}$ ) values for each sample and for each microsphere in each well were determined using the Bio-Plex Manager 6.1 software. Further data analysis was performed as described below (see Data Analysis).

Data Analysis. All data analyses (plotting, quantification, and statistical analyses) were performed using the open source statistics software $\mathrm{R}$ (version 3.5.1) (n) $^{27}$ in conjunction with the following packages. Data from the Bio-Plex 200 were exported to Microsoft Excel for subsequent import to $\mathrm{R}$ using the package readxl which is contained within the tidyverse package. A second Excel file containing metadata, such as plate layout and concentrations of the standard 13/132 for quantification, was also imported to $\mathrm{R}$ and merged in a data frame suited for subsequent analysis using the package $d r L u m i{ }^{28}$ Here a standard curve was generated for serum 13/132 using a fiveparameter nonlinear regression curve fit of the mfi values over international units with the negative control (buffer only) set as constraint. Subsequently, the absolute concentration of reactivity of the tested sera was expressed in international units by calculation using this standard curve. To determine the agreement between the results obtained by the multiplex assay and the reference methods, the linear regression was calculated between the log-transformed values of the quantified sera. The positive and negative control beads were used to exclude sera not fulfilling a quality control check (background binding to HSA beads below $500 \mathrm{mfi}$ (negative control) and binding to antihuman IgG beads above $10000 \mathrm{mfi}$ (positive control)) from the analysis ( 83 sera were analyzed). A receiver-operator curve was constructed using the $p R O C$ package. ${ }^{29}$ All plots were generated using the ggplot2 package contained within the tidyverse package. Finally, the agreement between the multiplex assay and a reference ELISA for a small panel of IgM positive sera $(n=20)$ was determined by calculating the Pearson's correlation coefficient between the ELISA data (either expressed in $\mathrm{IU} / \mathrm{mL}$ or IgM index) and the $\mathrm{mfi}$ data. Visualization of Figure 2 was performed with Prism 7 (GrapPad). 


\section{RESULTS}

Preparation of Glycans and Linkers. The glycan portions of GPI1 and the mannose 3 were synthesized on milligram scale following established protocols. ${ }^{23,24}$ To conjugate the glycans to the carboxylate beads via a thiol, an $\mathrm{N}$-propylaminomaleimide (NPM) linker 5 was prepared in $80 \%$ yield and two steps: coupling of maleimide 4 with 3-(Bocamino)-1-propanol using Mitsunobu conditions $(\mathrm{SI})^{30}$ followed by Boc-group removal using TFA (Scheme 1).

Scheme 1. Preparation of Maleimide-Functionalized Beads ${ }^{a}$
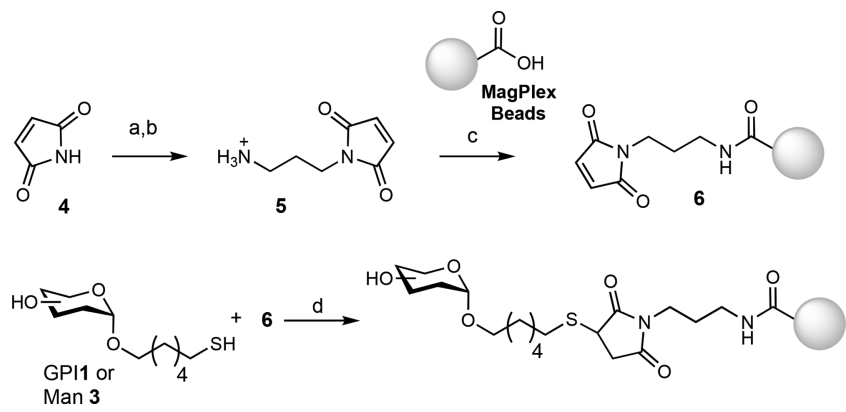

${ }^{a}$ Reagents and conditions: (a) BocHN- $\left(\mathrm{CH}_{2}\right)_{3}-\mathrm{OH}, \mathrm{PPh}_{3}, \mathrm{DIAD}$, THF, rt, $48 \mathrm{~h}$; (b) TFA, DCM, $\mathrm{H}_{2} \mathrm{O}, \mathrm{rt}, 5 \mathrm{~h}, 80 \%$ (over two steps); (c) MagPlex microspheres region 020, EDC, MES buffer $\mathrm{pH}$ 6.0; (d) i. TCEP, PBS buffer $\mathrm{pH} 7.0$, ii. Tris buffer $\mathrm{pH} 7.4$
Preparation of Glycan-Bead Conjugates. To establish the best conditions for glycan conjugation, carboxylated MagPlex microspheres $\left(5 \times 10^{5}\right.$ beads $)$ were modified with $100 \mu \mathrm{L}$ of linker 5 at $0.06,0.16,0.32,0.65$, and $1.30 \mathrm{mM}$ followed by reaction with $1.30 \mathrm{mM}$ Man 3 . Determination of the Man3 conjugation efficiency with a solution of FITClabeled concanavalin $\mathrm{A}$, a lectin-binding mannose, showed an increase in fluorescence for beads modified using between 6.5 and $65 \mathrm{nmol}$ of the linker. Higher amounts $(130 \mathrm{nmol})$ did not increase the fluorescence intensity, indicating saturation of the binding sites on the microspheres (Figure S1, SI). On the basis of this result, a $1 \mathrm{mg} / \mathrm{mL}\left(65 \mathrm{nmol} / 5 \times 10^{5}\right.$ beads $)$ solution of linker 5 was used in all further experiments to modify the microspheres. Then the GPI1 glycan was conjugated using 10 $\mu \mathrm{g}(6.6 \mathrm{nmol})$ of glycan $/ 5 \times 10^{5}$ beads. Acid hydrolysis of the GPI1 conjugate with TFA and further quantification of glucose using a HPAE-PAD chromatographic system showed a coupling of $770 \mathrm{pmol} / 10^{6}\left(1.16 \mu \mathrm{g}\right.$ of GPI1/10 $\left.0^{6}\right)$ beads (SI). Analysis of a second conjugation of GPI1 to the beads delivered a content of $1.36 \mu \mathrm{g}$ of GPI1 $/ 10^{6}$ beads, confirming the reproducibility of the conjugation and the determination.

Immunoreactivity of Coupled Antigens. To test the applicability of GPI1 coupled to magnetic beads for the detection of toxoplasmosis serostatus, a dilution series of reference sera (starting at 1:200 dilution), positive for T. gondii antibodies, was incubated with the 4-plex assay components consisting of GPI1- and SAG1-loaded beads in addition to HSA- and antihuman IgG-coupled beads (Figure $2 a$ and $2 b$ ). Both WHO reference sera were reactive against GPI1 and
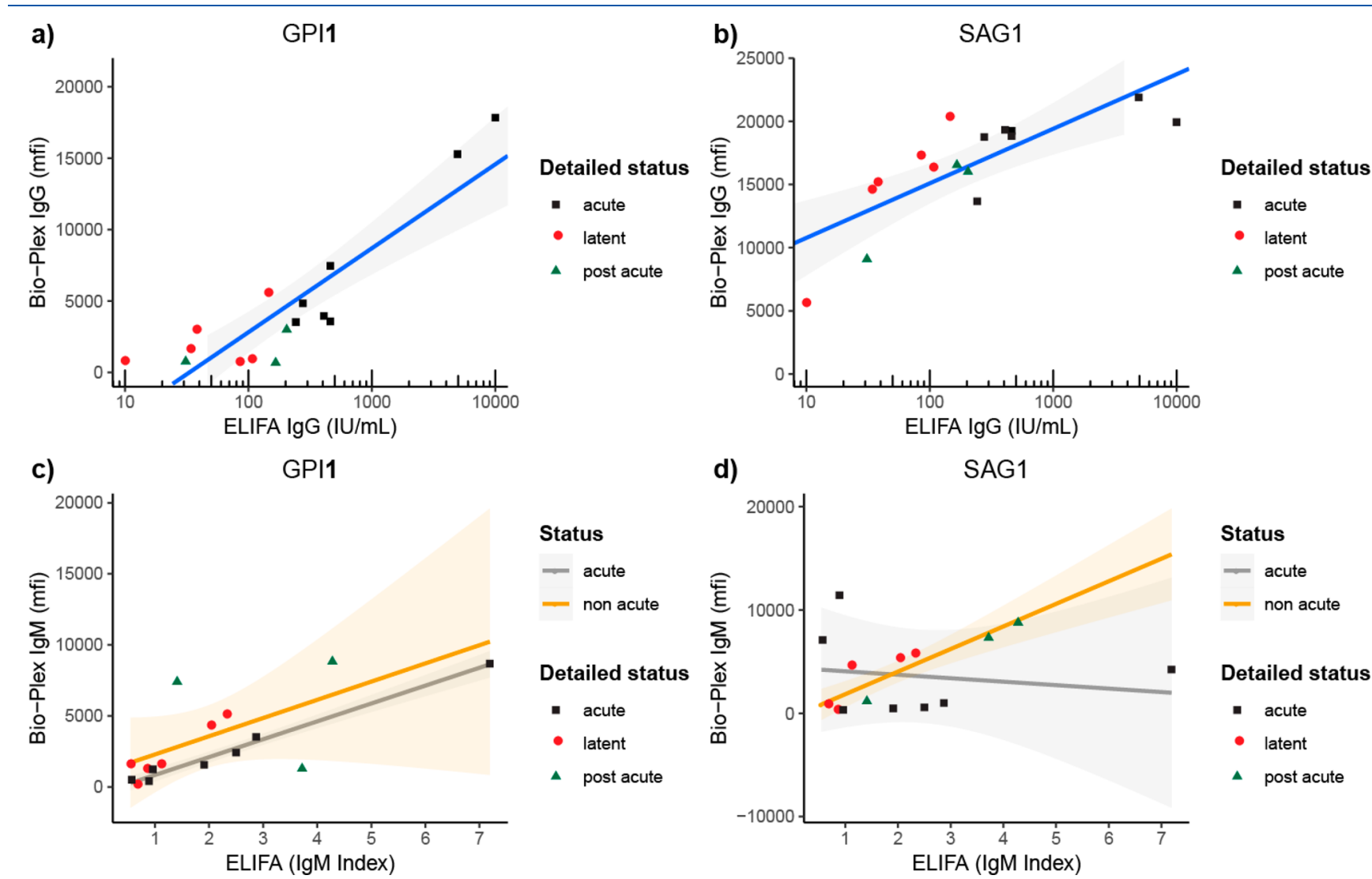

Figure 3. Correlation between IgG and IgM antibodies in a panel of 16 IgM-positive sera. Bio-Plex readout (mfi) vs ELIFA readout (IU or index) are shown for IgG response (a, b) or IgM response (c, d), and GPI1 beads (a, c) or SAG1 beads (b, d), respectively. Results are based on two independent experiments. Shaded areas indicate $95 \%$ CI. 
SAG1, with serum $13 / 132$ exhibiting stronger binding to both antigens when compared to serum $01 / 600$, which agrees with the higher content of $T$. gondii-specific antibodies. Binding to SAG1, the immunodominant antigen during a $T$. gondii infection, ${ }^{31}$ was higher for both reference sera as compared to GPI1. However, GPI1 was also recognized by both sera in a concentration-dependent manner and clearly above background binding to HSA.

Comparison of Microarrays and Bead Assay. Previously, we showed that GPI1 is a suitable antigen to detect acute phase IgM antibodies in a microarray-based platform. ${ }^{16}$ Thus, we were interested to see whether those results could be transferred to the BBMA. Detection of IgM antibodies using a microarray and BBMA was performed with sera from 19 patients, acutely infected with $T$. gondii. Correlation of the antiGPI1 IgM antibody binding levels showed an excellent agreement (linear regression $R^{2}=0.95$ ) between both methods (Figure 2c).

Validation of GPI1 and SAG1 Multiplex Assay Performance for Serosurveys. Using the standardized conditions, 88 human sera, previously characterized with a commercial ELISA that is based on parasite lysate (PBP sera, see Materials and Methods), were evaluated using the GPI1bead conjugate. To compare the potency of GPI1 glycan against a protein marker, determination of the serostatus using the BBMA assay was carried out using recombinant $S A G 1^{26,32}$ conjugated to beads of region 33. Additionally, antihuman IgG and human serum albumin (HSA) were included as positive and negative control beads, respectively, and used to exclude results that did not meet the quality criteria of $\mathrm{mfi}$ signals $>10000$ (antihuman IgG beads) and mfi signals <500 (HSA beads) in two independent experiments. Additionally, results were only valid if at least 50 independent events could be evaluated per bead region. Using a standard curve generated by fitting a five-parameter nonlinear regression to a dilution series of the WHO international reference standard 13/132, the binding to both SAG1 and GPI1 beads was expressed in international units (IU) per $\mathrm{mL}$ and compared to the results obtained by the commercial ELISA for 82 (SAG1) or 83 (GPI1) sera by linear regression (Figure $2 \mathrm{~d}$ and $2 \mathrm{e}$ ). The serostatus determined by IgG ELISA and the BBMA assay $\left(R^{2}\right.$ $=0.91$ for SAG1; $R^{2}=0.66$ for GPI1) was in very good agreement.

On the basis of these data, the ability to discriminate in PBP sera IgG-positive from -negative samples was determined for both SAG1 and GPI1 by the multiplex assay in comparison to the ELISA by receiver-operator curve (ROC) analysis. SAG1 allowed a perfect discrimination (area under curve $=1$ ) between positive and negative sera, while for GPI a clear separation (few false positive or false negative samples) was possible (area under curve $=0.98$ ). Using a threshold of 20.6 $\mathrm{IU} / \mathrm{mL}$ (95\% CI 17.9-24.5), a maximum sensitivity of $97.1 \%$ (95\% CI $88.2-100)$ was reached at a specificity of $98.0 \%$ (95\% CI 91.8-100) for the analysis of IgG antibodies with GPI1 as antigen (Figure $2 \mathrm{f}$ ).

Analysis of Sera for IgM Antibodies. To compare the BBMA results for both IgG and IgM with those from the reference measurements performed by enzyme-linked fluorescent assay (ELIFA), a panel of 16 sera from IgM-positive patients infected with $T$. gondii was analyzed. Correlation analysis for the IgG response showed robust and significant correlation between the ELIFA data (expressed in IU/mL) and the multiplex $\mathrm{mfi}$ results (Figure 3a,b) with Pearson's correlation coefficients of 0.78 for SAG1 $(p<0.001)$ and 0.89 for the GPI1-conjugate $(p<0.0001)$. Interestingly, the correlation between the BBMA and ELIFA data for IgM measurement was significantly higher for binding of acute sera to GPI1 beads (correlation coefficient of $0.9926, p=0.0088$ ), while no correlation was detected between IgM against SAG1 and ELIFA (Figure 3c). However, IgM indices of sera from postacute/latent infections correlated very well with $\operatorname{IgM} \mathrm{mfi}$ against SAG1 determined by BBMA (Figure 3d; correlation coefficient of $0.9232, p=0.0038)$ ). Although these data are based on only a small number of sera, they showed a differential response against the two defined antigens for discriminating very early from later infections.

\section{DISCUSSION}

Protozoan parasites are characterized by the presence of many free and protein-attached GPIs on the surface of the cell membrane. ${ }^{33}$ These glycolipids are potent modulators of the host immune system during infections and induce the production of antiglycan antibodies. ${ }^{34} T$. gondii displays two GPIs on the cell membrane that differ by the presence of a glucose unit in the glycan branch and the mode of presentation. The GPI containing glucose, also known as the low molecular weight antigen (LMWA), is found only as free glycolipid and is a strong activator of the host immune system. ${ }^{13}$ Previously, we demonstrated the presence of specific antibodies against this glycolipid in sera from $T$. gondii-infected individuals that can be used to determine the infection and the relevance of the glucose residue for the differentiation of antiGPI antibodies. ${ }^{23}$ Using the synthetic phosphoglycan GPI1 printed on microarrays and a set of reference sera a test was developed to detect seropositive sera and to differentiate the acute and latent stages of a T. gondii infection. ${ }^{16}$

To evaluate the potential of synthetic GPI1 for the determination of the $T$. gondii serostatus in humans using a BBMA, we first established the conjugation of the antigen to carboxylate microspheres. Various strategies for coupling glycan structures to carboxyl-functionalized beads have been described, e.g., via end-biotinylated $\mathrm{ABO}$ blood group glycans to streptavidin-coated beads, ${ }^{35}$ by functionalization of pneumococcal polysaccharides with 4-(4,6-dimethoxy[1,3,5]triazin-2-yl)-4-methyl-morpholinium (DMTMM) before adding to beads, ${ }^{36}$ or more classically by standard carbodiimidebased coupling protocols for glycans with a terminal amine group. $^{37-39}$ However, in the case of GPI1, the free amine groups of glucosamine and phosphoethanolamine are important for the specific binding of antibodies to GPIs. ${ }^{16,40}$ Thus, we selected a conjugation method using maleimideactivated beads and reaction with a thiol linker that is attached at the phospho-myo-inositol unit of GPI1 to retain the natural orientation of the glycan. Initial conjugation of the maleimide beads with a test compound (Man3) showed a concentration dependency and saturation of the binding sites using $65 \mathrm{nmol}$ of Man3 per $10^{5}$ beads. Considering the complexity, value, and size of GPI1, this glycan was conjugated using $6.5 \mathrm{nmol} / 10^{5}$ beads to get a loading of $1.1 \mu \mathrm{g}$ of GPI $1 / 10^{6}$ beads. This loading was in line with the theoretical capacity of the beads $\left(10^{8}\right.$ active sites/bead) and was reproducible between two different batches (SI).

Next, we established the use of the GPI1-bead conjugate for anti-GPI antibodies detection using BBMA in three steps. First, the detection of anti-GPI1 antibodies in the 13/132 and $01 / 600 \mathrm{WHO}$ reference sera was used to determine the 
immunoreactivity of the GPI-conjugate to distinguish seropositive samples. Then the detection of anti-GPI antibodies by BBMA was compared with the detection on microarrays using 19 characterized sera, and finally the BBMA was compared with a commercial ELISA test using a larger number of samples. The first two analyses showed good correlation and translation from microarrays to BBMA for both IgG and IgM anti-GPIs antibody detection and the possibility to quantify the immunoreactivity of the GPI-conjugates against established standards, which is required for proper standardization of the method. ${ }^{6}$ Antibody detection was performed using the full glycan of the LMWA (GPI1). Previously, we showed the detection of anti-GPI antibodies on microarrays using fragments of GPI1 with similar specificity as with the full glycan. ${ }^{16}$ These smaller fragments represent an alternative to GPI1 to use defined material with reduced complexity and production cost of the antigen without loss of specificity and selectivity in the assay.

The detection of anti-GPI1 IgM and IgG antibodies in sera from acute infected patients showed the induction of these antibodies at the initial stage of the infection. ${ }^{34}$ However, the detection of IgG serostatus by BBMA of $>80$ sera using GPI1 presented a lower correlation with the commercial ELISA test than BBMA using SAG1 as antigen. The correlation difference could derive from the sole usage of SAG1, which is the main immunogenic protein on the surface of tachyzoites ${ }^{31}$ and a low abundance or absence of the LMWA in the detergent extract of purified T. gondii parasites used as antigen in the commercial ELISA test.

The detection of antiglycan antibodies in ovarian cancer patients by three glycan immunoassays (ELISA, printed glycan array, and BBMA assay) has shown variable detection specificities that are influenced by factors such as density, surface presentation of glycans, and antibody/antigen ratios for each assay format. ${ }^{41}$ Therefore, each assay format has its own advantages and disadvantages. BBMA is suitable for diagnostic purposes in clinical settings, illustrated by the recently introduced commercial multiplex assay for the detection of IgM antibodies against $T$. gondii, rubella, and cytomegalovirus $(\text { ToRC })^{42-44}$ or for large-scale epidemiological surveys. ${ }^{10,45}$ We illustrate that the GPI1 glycan antigen works independently of the type of assay used and can be applied for the detection of both IgG and IgM antibodies, which might be a valuable addition to established commercial assays. Further studies should determine the reactivity of $\operatorname{IgA}$ and $\operatorname{IgE}$ antibodies, and the avidity of IgG antibodies toward GPIs, which may extend the applicability of this antigen to confirm an acute infection also in other assay formats. Moreover, the possibility of discrimination of very early from later infections by using SAG1 and GPI1 as antigens and combined with IgM serology needs to be substantiated with sera from a larger panel and also from different patient cohorts (immunocompromised patients, newborns from seropositive mothers, follow-up sera from the same seroconverters, etc.).

\section{CONCLUSION}

Synthetic glycan antigen GPI1 from $T$. gondii was conjugated to maleimide-modified carboxylate-beads to determine the anti-T. gondii serostatus using a bead-based multiplex assay. GPI1 was only slightly less sensitive and specific in detecting IgG antibodies in human sera than the protein antigen SAG1. However, GPI1 was better than SAG1 in detecting the IgM immune response during an early acute infection. Therefore,
GPI1 is an attractive candidate antigen to be included in multiplex bead-based assays for the early detection of a $T$. gondii infection.

\section{ASSOCIATED CONTENT}

\section{S Supporting Information}

The Supporting Information is available free of charge on the ACS Publications website at DOI: 10.1021/acs.analchem.9b02154.

Chemical protocols, analysis, and characterization of the glycan-bead conjugates, optimization of the BBMA, further data about the determination of $\operatorname{IgM}$, and pictures of the glycan arrays (PDF)

\section{AUTHOR INFORMATION}

\section{Corresponding Author}

*E-mail: daniel.varon@mpikg.mpg.de.

ORCID $\odot$

Daniel Stern: 0000-0001-9057-4283

Daniel Varón Silva: 0000-0003-2804-1923

\section{Author Contributions}

F.S., P.H.S., and D.V.S. conceived and supervised the experiments. M.G., D.S., F.S., and D.V.S. performed the experiments. M.G., F.S., and D.V.S. drafted the initial manuscript. F.S., D.S., P.H.S., U.G., and D.V.S. contributed crucial materials and data and reviewed the manuscript.

\section{Author Contributions}

\#Contributed equally.

\section{Notes}

The authors declare no competing financial interest.

\section{ACKNOWLEDGMENTS}

This work was supported by the Max Planck Society, the Riken-Max Planck Joint Center for Systems Chemical Biology, and the Robert Koch-Institute. P.H.S. and F.S. are senior members of GRK 2046, supported by the German Research Council. M.G. thanks the IMPRS for Multiscale Biosystems for financial support. We thank Katrin Sellrie, Sandra Pinzón, and Hyun-Il Oh for their support with the microarray analysis and the GPI quantification, and to Conny Müller, Olena Shatohina, and Sandra Klein for excellent technical assistance.

\section{REFERENCES}

(1) Montoya, J. G.; Liesenfeld, O. Lancet 2004, 363 (9425), 19651976.

(2) Schluter, D.; Daubener, W.; Schares, G.; Gross, U.; Pleyer, U.; Luder, C. Int. J. Med. Microbiol. 2014, 304 (7), 917-29.

(3) Robert-Gangneux, F.; Meroni, V.; Dupont, D.; Botterel, F.; Garcia, J. M. A.; Brenier-Pinchart, M. P.; Accoceberry, I.; Akan, H.; Abbate, I.; Boggian, K.; Bruschi, F.; Carratala, J.; David, M.; Drgona, L.; Djurkovic-Djakovic, O.; Farinas, M. C.; Genco, F.; GkraniaKlotsas, E.; Groll, A. H.; Guy, E.; Hirzel, C.; Khanna, N.; Kurt, O.; Junie, L. M.; Lazzarotto, T.; Len, O.; Mueller, N. J.; Munoz, P.; Pana, Z. D.; Roilides, E.; Stajner, T.; van Delden, C.; Villena, I.; Pelloux, H.; Manuel, O. Emerging Infect. Dis. 2018, 24 (8), 1497-1504.

(4) Remington, J. S.; McLeod, R.; Wilson, C. B.; Desmonts, G. Toxoplasmosis. In Infectious Diseases of the Fetus and Newborn, 7th ed.; Remington, J. S.; Klein, J. O.; Wilson, C. B.; Nizet, V.; Maldonado, Y. A., Eds.; W.B. Saunders: Philadelphia, 2011; Chapter 31, pp 9181041.

(5) Robert-Gangneux, F.; Dardé, M.-L. Clin. Microbiol. Rev. 2012, 25 (2), 264-296. 
(6) Zhang, K.; Lin, G.; Han, Y.; Li, J. Clin. Chim. Acta 2016, 461, 83-9.

(7) Liu, Q.; Wang, Z. D.; Huang, S. Y.; Zhu, X. Q. Parasites Vectors 2015, 8, 292.

(8) Pomares, C.; Montoya, J. G. J. Clin. Microbiol. 2016, 54 (10), 2448-54.

(9) Jani, I. V.; Janossy, G.; Brown, D. W.; Mandy, F. Lancet Infect. Dis. 2002, 2 (4), 243-50.

(10) Metcalf, C. J. E.; Farrar, J.; Cutts, F. T.; Basta, N. E.; Graham, A. L.; Lessler, J.; Ferguson, N. M.; Burke, D. S.; Grenfell, B. T. Lancet 2016, 388 (10045), 728-730.

(11) Priest, J. W.; Moss, D. M.; Arnold, B. F.; Hamlin, K.; Jones, C. C.; Lammie, P. J. Epidemiol. Infect. 2015, 143 (3), 618-30.

(12) Graham, H.; Chandler, D. J.; Dunbar, S. A. Methods 2019, 158, $2-11$.

(13) Striepen, B.; Zinecker, C. F.; Damm, J. B.; Melgers, P. A.; Gerwig, G. J.; Koolen, M.; Vliegenthart, J. F.; Dubremetz, J. F.; Schwarz, R. T. J. Mol. Biol. 1997, 266 (4), 797-813.

(14) Jung, C.; Lee, C. Y.; Grigg, M. E. Int. J. Parasitol. 2004, 34 (3), 285-96.

(15) Azzouz, N.; Shams-Eldin, H.; Niehus, S.; Debierre-Grockiego, F.; Bieker, U.; Schmidt, J.; Mercier, C.; Delauw, M. F.; Dubremetz, J. F.; Smith, T. K.; Schwarz, R. T. Int. J. Biochem. Cell Biol. 2006, 38 (11), 1914-25.

(16) Gotze, S.; Azzouz, N.; Tsai, Y. H.; Gross, U.; Reinhardt, A.; Anish, C.; Seeberger, P. H.; Varon Silva, D. Angew. Chem., Int. Ed. 2014, 53 (50), 13701-13705.

(17) Arnold, B. F.; Scobie, H. M.; Priest, J. W.; Lammie, P. J. Emerging Infect. Dis. 2018, 24 (7), 1188-1194.

(18) Pöhn, H. P.; Rasch, G. Statistik meldepflichtiger übertragbarer Krankheiten; MWV Medizin Verlag: München, 1994; p 219.

(19) Bothig, B.; Danes, L.; Gerike, E.; Ditmann, S.; Svandova, E. J. Hyg. Epidemiol. Microbiol. Immunol. 1992, 36 (3), 269-78.

(20) Dard, C.; Bailly, S.; Drouet, T.; Fricker-Hidalgo, H.; BrenierPinchart, M. P.; Pelloux, H. J. Microbiol. Methods 2017, 134, 38-45.

(21) Rijpkema, S.; Hockley, J.; Rigsby, P.; Guy, E. C. Biologicals 2016, 44 (5), 448-455.

(22) Rigsby, P.; Rijpkema, S.; Guy, E. C.; Francis, J.; Gaines Das, R. J. Clin. Microbiol. 2004, 42 (11), 5133-5138.

(23) Tsai, Y. H.; Gotze, S.; Azzouz, N.; Hahm, H. S.; Seeberger, P. H.; Varon Silva, D. Angew. Chem., Int. Ed. 2011, 50 (42), 9961-4.

(24) Tsai, Y. H.; Gotze, S.; Vilotijevic, I.; Grube, M.; Silva, D. V.; Seeberger, P. H. Chem. Sci. 2013, 4 (1), 468-481.

(25) Stephen, A.; Sherry, D.; Carlos, G.; Valerie, S. $x M A P ®$ Cookbook; 3rd ed.; Luminex Corp., 2016; p 147.

(26) Ferreira, S. C. M.; Torelli, F.; Klein, S.; Fyumagwa, R.; Karesh, W. B.; Hofer, H.; Seeber, F.; East, M. L. Int. J. Parasitol. Parasites Wildl. 2019, 8, 111-117.

(27) R Core Team. R: A language and environment for statistical computing; R Foundation for Statistical Computing: Vienna, Austria, 2018.

(28) Sanz, H.; Aponte, J.; Harezlak, J.; Dong, Y.; Murawska, M.; Valim, C. drLumi: Multiplex immunoassays data analysis; R package version 0.1.2.; 2015.

(29) Robin, X.; Turck, N.; Hainard, A.; Tiberti, N.; Lisacek, F.; Sanchez, J.-C.; Müller, M. J. B. B. BMC Bioinf. 2011, 12 (1), 77.

(30) Bertozzi, C. R.; Agard, N. J.; Prescher, J. A.; Baskin, J. M.; Sletten, E. M. Preparation of cyclooctynes and azacyclooctynes for modification of biomolecules in vivo and in vitro by their copper-free strain-promoted $[3+2]$ cycloaddition with azides. US Patent US20090068738A1, 2009.

(31) Wang, Y.; Yin, H. Parasites Vectors 2014, 7, 180-180.

(32) Fujii, Y.; Kaneko, S.; Nzou, S. M.; Mwau, M.; Njenga, S. M.; Tanigawa, C.; Kimotho, J.; Mwangi, A. W.; Kiche, I.; Matsumoto, S.; Niki, M.; Osada-Oka, M.; Ichinose, Y.; Inoue, M.; Itoh, M.; Tachibana, H.; Ishii, K.; Tsuboi, T.; Yoshida, L. M.; Mondal, D.; Haque, R.; Hamano, S.; Changoma, M.; Hoshi, T.; Kamo, K.-i.; Karama, M.; Miura, M.; Hirayama, K. PLoS Neglected Trop. Dis. 2014, 8 (7), e3040.
(33) Tsai, Y.-H.; Grube, M.; Seeberger, P. H.; Varon Silva, D. Trends Glycosci. Glycotechnol. 2012, 24 (140), 231-243.

(34) Debierre-Grockiego, F.; Schwarz, R. T. Glycobiology 2010, 20 (7), 801-811.

(35) Pochechueva, T.; Chinarev, A.; Spengler, M.; Korchagina, E.; Heinzelmann-Schwarz, V.; Bovin, N.; Rieben, R. Analyst 2011, 136 (3), 560-9.

(36) Schlottmann, S. A.; Jain, N.; Chirmule, N.; Esser, M. T. J. Immunol. Methods 2006, 309 (1-2), 75-85.

(37) Chandrasekaran, A.; Deng, K.; Koh, C. Y.; Takasuka, T.; Bergeman, L. F.; Fox, B. G.; Adams, P. D.; Singh, A. K. Chem. Commun. 2013, 49 (48), 5441-5443.

(38) Purohit, S.; Li, T.; Guan, W.; Song, X.; Song, J.; Tian, Y.; Li, L.; Sharma, A.; Dun, B.; Mysona, D.; Ghamande, S.; Rungruang, B.; Cummings, R. D.; Wang, P. G.; She, J. X. Nat. Commun. 2018, 9 (1), 258.

(39) Gurale, B. P.; He, Y.; Cui, X.; Dinh, H.; Dhawane, A. N.; Lucchi, N. W.; Udhayakumar, V.; Iyer, S. S. Bioconjugate Chem. 2016, 27 (12), 2886-2899.

(40) Kamena, F.; Tamborrini, M.; Liu, X. Y.; Kwon, Y. U.; Thompson, F.; Pluschke, G.; Seeberger, P. H. Nat. Chem. Biol. 2008, 4 (4), 238-240.

(41) Pochechueva, T.; Jacob, F.; Goldstein, D. R.; Huflejt, M. E.; Chinarev, A.; Caduff, R.; Fink, D.; Hacker, N.; Bovin, N. V.; Heinzelmann-Schwarz, V. Glycoconjugate J. 2011, 28 (8-9), 507-17.

(42) Guigue, N.; Menotti, J.; Hamane, S.; Derouin, F.; Garin, Y. J. Clin. Vaccine Immunol. 2014, 21 (4), 496-500.

(43) Binnicker, M. J.; Jespersen, D. J.; Harring, J. A. Clin. Vaccine Immunol. 2010, 17 (11), 1734-8.

(44) Theel, E. S.; Yarbrough, M. L.; Hilgart, H.; Gronowski, A. M. J. Appl. Lab. Med. 2019, 3, 1022.

(45) Arnold, B. F.; van der Laan, M. J.; Hubbard, A. E.; Steel, C.; Kubofcik, J.; Hamlin, K. L.; Moss, D. M.; Nutman, T. B.; Priest, J. W.; Lammie, P. J. PLoS Neglected Trop. Dis. 2017, 11 (5), e0005616. 